\title{
A Strategic R\&D Investment with Flexible Development Time in Real Option Game Analysis
}

\author{
GIOVANNI VILLANI
}

\author{
CESIFO WorkING PAPER No. 2728 \\ CATEGORY 12: EMPIRICAL AND THEORETICAL METHODS \\ JULY 2009
}

Presented At CESifo Venice Summer Institute, July 2009

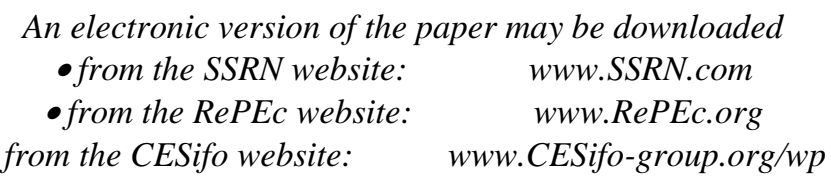




\title{
A Strategic R\&D Investment with Flexible Development Time in Real Option Game Analysis
}

\begin{abstract}
The real option theory provides a useful tool to evaluate an $R \& D$ investment under uncertainty because, unlike the NPV (Net Present Value), it considers the managerial flexibility that may be expand the investment opportunity value. However, most R\&D investment projects are open to competing firms in the same industry or line of business, and so the strategic considerations become extremely important. In this paper we analyze a real option game between two firms that invest in R\&D. The firm that invests first, defined as the Leader, acquires a first mover advantage that we assume as a higher market share than other one, namely the Follower, that postpones its $R \& D$ investment decision. But, several R\&D investments present positive externalities and so, the option exercise by the Leader generates an "Information Revelation" that benefits the Follower. Moreover, to value the flexibility time to realize the development phase, we consider the American-Exchange type options.
\end{abstract}

JEL Code: G13, C72, C15, O32, D80.

Keywords: American Exchange options, game theory, Montecarlo simulation, R\&D, information revelation.

\author{
Giovanni Villani \\ Department of Economics, Mathematics and Statistics \\ University of Foggia \\ Largo Papa Giovanni Paolo II \\ 71100 Foggia \\ Italy \\ g.villani@unifg.it
}




\section{Introduction}

The innovation is one of the important key strategies for firms to survive. Therefore, Research and Development (R\&D) investment plays an important role in the successful performance for a firm. During the last two decades, the application of option pricing formula to $R \& D$ has become of interest and numerous studies have attempted to address how the real options analysis can help draw the proper line between knowledge building and strategic positioning. In fact it is widely recognised that the conventional NPV rule could in principle underestimate the value of an R\&D project because this method fails to take the managerial flexibility into account. From a modelling perspective, real $R \& D$ options valuation methods have tended to follow financial option pricing techniques. Analogous to financial options on stocks, real options are options on real or physical assets such as technologies, production facilities and so on. When a firm "invests" means that it exercises its option by involving an initial cost to exchange for a real asset. According to Copeland \& Antikarov (2003), a real option is "the right, but not the obligation, to take an action (e.g. deferring, expanding, contracting, or abandoning) at a predetermined cost called the exercise price, for a predetermined period of time - the life of option".

Several models, such as is assumed to be in Majd \& Pindyck (1987), Trigeorgis (1991), Lee (1997), are based on this definition, in which the exercise price is fixed. But, for the evaluation of real R\&D investment opportunity, it is appropriate to consider that also the investment cost is uncertain since the manager cannot make an accurate estimate of the future costs. So the R\&D investment opportunity corresponds to an exchange option: it's the exchange of an uncertain investment cost for an uncertain gross project value. The most relevant models that value investment opportunities with two stochastic variables are given in Margrabe (1978), McDonald \& Siegel (1985), Carr (1988), Carr (1995), Armada et al. (2007).

Margrabe (1978) developed a model to price the simple European exchange option (SEEO) to exchange one risky asset for another one at maturity date $T$ and McDonald \& Siegel (1985) considered that the assets distribute dividends. In a real options context, "dividends" are the opportunity costs inherent in the decision to defer an investment project. Furthermore, in a real options context, deferment implies the loss of the project's cash flows. Carr (1988) model, building on Margrabe (1978) and Geske (1979), provided the valuation of compound European exchange options (CEEO). This model may be interpreted as a combination of a time-to-build option (growth option) and an option to exchange (operating option). In addition, Carr (1988), Carr (1995) Armada et al. (2007) provided an approximation to value a simple American exchange option (SAEO). When the asset to be received in the exchange pays large dividend yields, there is always a probability that the American exchange option will be exercised prior to expiration. This means that managers have the timing choice for the development phase realization that gives the opportunity to capture the project's cash flows.

Moreover, competitive interaction becomes fundamentally important in the valuation and exercise of real options, while it may not be such a significant concern for financial options. Such competitive interactions may have profound effects on option exercise decisions and the resulting equilibrium. Real options and game-theory thinking have been embraced by strategic decision-makers who recognise the importance of making an early investment commitment (game theory) while maintaining managerial flexibility (real options) to adapt their choices to a changing market environment.

The aim of this paper is to analyse a real option game model between two firms that 
invest in R\&D. The first firm that invests, defined as the Leader, acquires a first mover advantage that we assume as a highest market share. But, several R\&D investments, present positive externalities and so, the option exercise by the Leader, generates an "Information Revelation" that benefits the Follower. Moreover, to consider the managerial flexibility to realize the development investment $D$, we assume that the opportunity to entry in the market is like an American exchange option.

This paper follows the Dias \& Teixeira (2004), Villani (2008) and Cortelezzi \& Villani (2008) models that analyze the equilibrium strategies of two firms that invest in R\&D assuming the uncertainty about the R\&D implementation and also considering the information revelation process. We differentiate from them because we use American exchange options to value the stochastic processes for R\&D costs $(D$ and $R$ ) and for overall market value $V$ deriving by R\&D innovations and also to consider the managerial flexibility to realize the development investment $D$.

The paper is organized as follows. Section 2 reviews some of the relevant American option pricing literature while Section 3 derives the final payoffs of two firms. In Section 4 , we present a real model implementation with computation of critical market values that delimit the several Nash equilibriums and, in Section 5, we analyze the effects that the most important parameters have on the game ranges. Finally, Section 6 concludes.

\section{Exchange Options Methodology}

In this section we present the final results to value American exchange options.

\subsection{Simple American exchange option (SAEO)}

Carr (1988) and Carr (1995) models give us the value of a Pseudo American exchange option (PSAEO). In particular way, let $t_{0}=0$ the evaluation date and $T$ the maturity date of the exchange option, we assume that $V$ and $D$ follow a geometric Brownian motion process given by:

$$
\begin{gathered}
\frac{d V}{V}=\left(\mu_{v}-\delta_{v}\right) d t+\sigma_{v} d Z_{v} \\
\frac{d D}{D}=\left(\mu_{d}-\delta_{d}\right) d t+\sigma_{d} d Z_{d} \\
\operatorname{cov}\left(\frac{d V}{V}, \frac{d D}{D}\right)=\rho_{v d} \sigma_{v} \sigma_{d} d t
\end{gathered}
$$

where $V$ and $D$ are the Gross Project Value and the Investment Cost, respectively, $\mu_{v}$ and $\mu_{d}$ are the equilibrium expected rate of return on asset $V$, and the expected growth rate of the investment cost, $\delta_{v}$ and $\delta_{d}$ are the "dividend-yields" of $V$ and $D$, $Z_{v}$ and $Z_{d}$ are the Brownian standard motions of asset $V$ and $D, \sigma_{v}$ and $\sigma_{d}$ are the volatility of $V$ and $D$ respectively, $\rho_{v d}$ is the correlation between changes in $V$ and $D$. Carr (1988) shows that the value of a PSAEO $\left(S_{2}\right)$ exercisable at time $\frac{T}{2}$ or $T$ is:

$$
\begin{aligned}
S_{2}(V, D, T)= & V e^{-\delta_{v} T} N_{2}\left(-d_{1}^{*}, d_{1} ;-\rho_{1}\right)-D e^{-\delta_{d} T} N_{2}\left(-d_{2}^{*}, d_{2} ;-\rho_{1}\right) \\
& +V e^{-\delta_{v} \frac{T}{2}} N\left(d_{1}^{*}\right)-D e^{-\delta_{d} \frac{T}{2}} N\left(d_{2}^{*}\right)
\end{aligned}
$$

where:

$$
\text { - } P=\frac{V}{D} ; \quad \sigma=\sqrt{\sigma_{v}^{2}-2 \rho_{v, d} \sigma_{v} \sigma_{d}+\sigma_{d}^{2}} ; \quad \delta=\delta_{v}-\delta_{d}
$$


- $d_{1} \equiv d_{1}(P, T)=\frac{\log P+\left(\frac{\sigma^{2}}{2}-\delta\right) T}{\sigma \sqrt{T}} ; \quad d_{2}(P, T)=d_{1}(P, T)-\sigma \sqrt{T} ;$

- $d_{1}^{*} \equiv d_{1}\left(\frac{P}{P^{*}}, \frac{T}{2}\right)=\frac{\log \left(\frac{P}{P^{*}}\right)+\left(\frac{\sigma^{2}}{2}-\delta\right) \frac{T}{2}}{\sigma \sqrt{\frac{T}{2}}} ;$

- $d_{2}^{*} \equiv d_{2}\left(\frac{P}{P^{*}}, \frac{T}{2}\right)=d_{1}^{*}-\sigma \sqrt{\frac{T}{2}} ; \quad \rho_{1}=\sqrt{\frac{T}{2 \cdot T}}=\sqrt{0.5}$;

- $N(d)$ is the cumulative standard normal distribution;

- $N_{2}\left(x_{1}, x_{2} ; \rho\right)$ is the standard bivariate normal distribution function evaluated at $x_{1}$ and $x_{2}$ with correlation $\rho$;

- $P^{*}$ is the unique value which makes indifferent the option exercise or not at time $\frac{T}{2}$ and it solves the following equation:

$$
P^{*} e^{-\delta_{v} \frac{T}{2}} N\left(d_{1}\left(P^{*}, \frac{T}{2}\right)\right)-e^{-\delta_{d} \frac{T}{2}} N\left(d_{2}\left(P^{*}, \frac{T}{2}\right)\right)=P^{*}-1
$$

Moreover, Armada et al. (2007) correct the two-moments extrapolation given in Carr (1988) and Carr (1995) to approximate the value of a simple American exchange option $S(V, D, T)$. So, using the Armada et al. (2007) formula, we have that:

$$
S(V, D, T) \simeq S_{2}(V, D, T)+\frac{S_{2}(V, D, T)-s(V, D, T)}{3}
$$

where $s(V, D, T)$ is the value of a simple European exchange option (SEEO) given by McDonald \& Siegel (1985):

$$
s(V, D, T)=V e^{-\delta_{v} T} N\left(d_{1}(P, T)\right)-D e^{-\delta_{d} T} N\left(d_{2}(P, T)\right)
$$

\subsection{Compound American exchange option (CAEO)}

Exchange option are simple or compound. If the underlying asset is another option, then the option is called compound. The underlying asset of a CAEO is the SAEO $S(V, D, \tau)$, the expiration date is $t_{1}$ and, following Carr (1988), the exercise price of a CAEO is a proportion $\varphi$ of asset $D$. Using Armada et al. (2007) extrapolation, we can approximate the value of a $\mathrm{CAEO}$ as:

$$
C\left(S(V, D, \tau), \varphi D, t_{1}\right) \simeq \frac{4 c_{2}\left(S_{2}(V, D, \tau), \varphi D, t_{1}\right)-c\left(s(V, D, \tau), \varphi D, t_{1}\right)}{3}
$$

where:

- $\tau=T-t_{1}$ is the time to maturity of the SAEO with $t_{1}<T$;

- $c_{2}\left(S_{2}(V, D, \tau), \varphi D, t_{1}\right)$ is the Pseudo compound American exchange option (PCAEO) whose underlying asset is the PAEO $S_{2}(V, D, \tau)$ that can be exercised at middle $\frac{\tau}{2}$ and final time $T$, the maturity date is time $t_{1}$ and the exercise price is a proportion $\varphi$ of asset $D$;

- $c\left(s(V, D, \tau), \varphi D, t_{1}\right)$ is the value of a compound European exchange option (CEEO) whose underlying asset is the simple European exchange option (SEEO) $s(V, D, \tau)$.

The value of PCAEO can be determined using Montecarlo simulation as illustrated in Cortelezzi \& Villani (2009). 


\section{The Basic Model Game}

In our model we consider a competitive interaction between two firms ( $A$ and $B$ ) face an R\&D investment opportunity. Both firms can decide to invest at time $t_{0}$ or to wait to invest and so to postpone their decision at time $t_{1}$. As it is know, the R\&D investments are uncertain and so, assuming by $q$ and $p$ the R\&D success probability of firms $\mathrm{A}$ and $\mathrm{B}$ respectively, we can represent this situation by two Bernoulli distributions $Y$ and $X$ :

$$
Y:\left\{\begin{array}{cc}
1 & q \\
0 & 1-q
\end{array} \quad X:\left\{\begin{array}{cc}
1 & p \\
0 & 1-p
\end{array}\right.\right.
$$

The value of $q$ and $p$ depend by the Know-How that each player holds on. Moreover, as it shown in Dias (2004), the R\&D success or failure of one firm generates an information revelation that influences the investment decision of the other firm. So, if firm A's R\&D is successful, the firm B's probability $p$ changes in positive information revelation $p^{+}$, while $p$ changes in negative information revelation $p^{-}$in case of A's failure. Symmetrically, the firm A's R\&D success changes in $q^{+}$or in $q^{-}$in case of firm B success or failure at time $t_{0}$. Using Dias (2004) model, it results that:

$$
\begin{aligned}
& p^{+}=\operatorname{Prob}[X=1 / Y=1]=p+\sqrt{\frac{1-q}{q}} \cdot \sqrt{p(1-p)} \cdot \rho(X, Y) \\
& p^{-}=\operatorname{Prob}[X=1 / Y=0]=p-\sqrt{\frac{q}{1-q}} \cdot \sqrt{p(1-p)} \cdot \rho(X, Y) \\
& q^{+}=\operatorname{Prob}[Y=1 / X=1]=q+\sqrt{\frac{1-p}{p}} \cdot \sqrt{q(1-q)} \cdot \rho(Y, X) \\
& q^{-}=\operatorname{Prob}[Y=1 / X=0]=q-\sqrt{\frac{p}{1-p}} \cdot \sqrt{q(1-q)} \cdot \rho(Y, X)
\end{aligned}
$$

where the correlations $\rho(X, Y)$ and $\rho(Y, X)$ are a measure of information revelation from $Y$ to $X$ and from $X$ to $Y$, respectively. Obviously, the information revelation is considerable when the investment is not realized in the same time. So, if both players invest simultaneously in R\&D or they wait to invest, there is not information revelation and consequently it results that $p=p^{+}=p^{-}$and $q=q^{+}=q^{-}$.

Under the threat of competition, the exercise of options strategically depends on the trade-off between the benefits and costs of going ahead with an investment against waiting for more information. So we state that the Leader is the pioneer firm (A or $\mathrm{B})$ that invests in $\mathrm{R} \& \mathrm{D}$ at time $t_{0}$ earlier than other one, namely the Follower, that defers exercising its option at time $t_{1}$ to receive better information. Leader can take an advantage of being first in the market and, in particular way, we suppose that it achieves the market share opportunity $\alpha \in\left(\frac{1}{2}, 1\right]$ of $\mathrm{V}$ higher than Follower's one, that is $1-\alpha$. But, if the investment is realized in the same time, both players share the market equally and so $\alpha=\frac{1}{2}$.

We denote by $R$ the R\&D investment for the development of a new product, $V$ the overall market value deriving by $\mathrm{R} \& \mathrm{D}$ innovations and $D$ is the total investment cost to realize new goods. We consider that the production investment of each firm is proportional to its market share and it can be realized at anytime before $T$ so we consider the managerial flexibility to realize the investment $D$. Therefore, the option to enter in the market is like an American exchange option. In particular, we assume that $V$ and $D$ follow the geometric Brownian motion defined in the Eqs.(1) and (2) respectively, and $R=\varphi D$ is a proportion $\varphi$ of asset $D$, so $R$ assumes the identical 
stochastic process of $D$ except that it can be spent only at initial time $t_{0}$ or at time $t_{1}$.

\subsection{The Follower's payoff.}

First of all, we analyze the game in which the firm A (Leader) invests in R\&D at time $t_{0}$ and the firm $\mathrm{B}$ (Follower) decides to delay its $\mathrm{R} \& \mathrm{D}$ investment decision at time $t_{1}$. So, assuming the Leader's R\&D success, the Follower's R\&D success probability changes in $p^{+}$and, after the investment $R$, the Follower holds the development option $S((1-\alpha) V,(1-\alpha) D, \tau)$ to invest $(1-\alpha) D$ at anytime from $t_{1}$ and $T$ and claims a share $1-\alpha$ of the overall market $V$. Of course, the investment $R$ will be realized at time $t_{1}$ if the development option $p^{+} S((1-\alpha) V,(1-\alpha) D, \tau)$ is bigger than $R$. So, the Follower's payoff at time $t_{0}$ is a CAEO with maturity $t_{1}$, exercise price equal to $R$ and the underlying asset is the development option $S((1-\alpha) V,(1-\alpha) D, \tau)$, as shown in Fig.1(a).

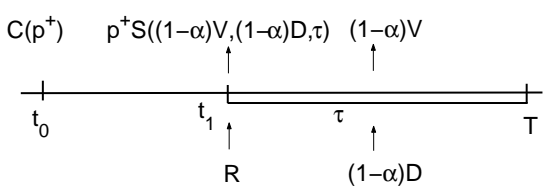

(a) Follower's Payoff in case of Leader's success

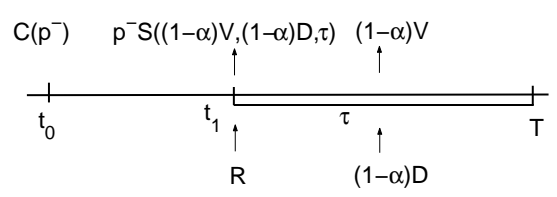

(b) Follower's Payoff in case of Leader's failure

Figure 1: Follower's payoffs

The CAEO payoff at expiration date $t_{1}$ with positive information revelation is:

$$
C\left(p^{+} S((1-\alpha) V,(1-\alpha) D, \tau), R, 0\right)=\max \left[p^{+} S((1-\alpha) V,(1-\alpha) D, \tau)-R, 0\right]
$$

Considering that $R=\varphi D$ is a proportion $\varphi$ of asset $D$ and denoting with $C\left(p^{+}\right)$the CAEO at time $t_{0}$, i.e.:

$$
C\left(p^{+}\right) \equiv C\left(p^{+} s((1-\alpha) V,(1-\alpha) D, \tau), \varphi D, t_{1}\right)
$$

we can write, using the Eq.(8), the value of CAEO with positive information:

$C\left(p^{+}\right) \simeq \frac{4 c_{2}\left(p^{+} S_{2}((1-\alpha) V,(1-\alpha) D, \tau), \varphi D, t_{1}\right)-c\left(p^{+} s((1-\alpha) V,(1-\alpha) D, \tau), \varphi D, t_{1}\right)}{3}$

Alternatively, in case of Leader's R\&D failure, the Follower success probability changes in $p^{-}$and the Follower holds, after the investment $R$ at time $t_{1}$, the development option $S((1-\alpha) V,(1-\alpha) D, \tau)$ to invest $(1-\alpha) D$ at anytime between $t_{1}$ and $T$ and claims the market value $(1-\alpha) V$. So the Follower's payoff at time $t_{0}$ is a CAEO with maturity $t_{1}$, exercise price equal to $R$ and the underlying asset is the development option $S((1-\alpha) V,(1-\alpha) D, \tau)$ as shown in Fig. 1(b). Hence, the CAEO payoff with negative information revelation at expiration date $t_{1}$ is:

$$
C\left(p^{-} S((1-\alpha) V,(1-\alpha) D, \tau), R, 0\right)=\max \left[p^{-} S((1-\alpha) V,(1-\alpha) D, \tau)-R, 0\right]
$$

So, denoting with $C\left(p^{-}\right)$the CAEO at time $t_{0}$, i.e.:

$$
C\left(p^{-}\right) \equiv C\left(p^{-} S((1-\alpha) V,(1-\alpha) D, \tau), \varphi D, t_{1}\right)
$$


we can write, using the Eq.(8), the value of CAEO with negative information:

$C\left(p^{-}\right) \simeq \frac{4 c_{2}\left(p^{-} S_{2}((1-\alpha) V,(1-\alpha) D, \tau), \varphi D, t_{1}\right)-c\left(p^{-} s((1-\alpha) V,(1-\alpha) D, \tau), \varphi D, t_{1}\right)}{3}$

The Follower obtains the CAEO $C\left(p^{+}\right)$in case of Leader's success with a probability $q$ or the CAEO $C\left(p^{-}\right)$in case of Leader's failure with a probability $(1-q)$. Hence, the Follower's payoff at time $t_{0}$ is the expectation value:

$$
F_{B}(V, D)=q C\left(p^{+}\right)+(1-q) C\left(p^{-}\right)
$$

Similarly, if we consider that firm B (Leader) invests in R\&D at time $t_{0}$ and firm A (Follower) decides to wait to invest it results:

$$
F_{A}(V, D)=p C\left(q^{+}\right)+(1-p) C\left(q^{-}\right)
$$

Using Cortelezzi \& Villani (2009) model, we are able to determine the Follower's payoff through Montecarlo simulation. In particular way, the appendix (A) shows the Matlab algorithm to obtain the values given by Eqs. (11) and (12).

\subsection{The A and B payoffs when both firms invest simultaneously in R\&D.}

In this situation, both players decide to realize the $R \& D$ investment simultaneously at time $t_{0}$. Hence, we can setting that there is not information revelation and consequently it results that $\rho(Y, X)=\rho(X, Y)=0$. Since the investment $R$ is equal for both firms, we assume that A and B can capture the same fraction $\alpha=\frac{1}{2}$ of the overall market value. So, after the investment $R$ in $t_{0}$, A and B hold with a probability $q$ and $p$ respectively, the development option $S\left(\frac{1}{2} V, \frac{1}{2} D, T\right)$ to invest $\frac{1}{2} D$ at anytime before $T$, as illustrated in the Figs. 2(a) and 2(b).

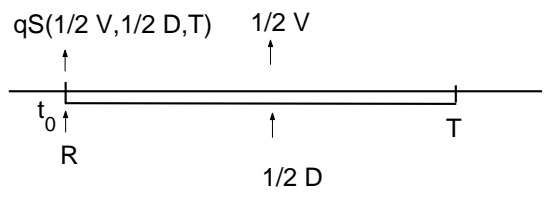

(a) Firm A's payoff

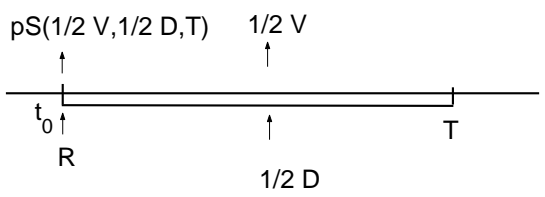

(b) Firm B's payoff

Figure 2: A and B payoffs in case of simultaneous investment

According to Eq.(6), we can write the A and B payoffs in case of simultaneous R\&D investment at time $t_{0}$ as:

$$
\begin{aligned}
S_{A}(V, D) & =-R+q \cdot S\left(\frac{1}{2} V, \frac{1}{2} D, T\right) \\
& \simeq-R+q\left(\frac{4 S_{2}\left(\frac{1}{2} V, \frac{1}{2} D, T\right)-s\left(\frac{1}{2} V, \frac{1}{2} D, T\right)}{3}\right) \\
S_{B}(V, D) & =-R+p \cdot S\left(\frac{1}{2} V, \frac{1}{2} D, T\right) \\
& \simeq-R+p\left(\frac{4 S_{2}\left(\frac{1}{2} V, \frac{1}{2} D, T\right)-s\left(\frac{1}{2} V, \frac{1}{2} D, T\right)}{3}\right)
\end{aligned}
$$




\subsection{The Leader's payoff}

Now we analyse the game in which firm A (Leader) invests in R\&D at time $t_{0}$, assuming that firm B (Follower) decides to postpones its decision waiting better information. In this case, the Leader spends the investment $R$ at time $t_{0}$ and obtains, in case of success with a probability $q$, the development option $S(\alpha V, \alpha D, T)$ that gives the opportunity to invest $\alpha D$ at anytime before $T$ and to claim a market share $\alpha>\frac{1}{2}$, as illustrated in the Fig. 3. Thus the Leader's payoff (firm A) will be:

$$
\begin{aligned}
L_{A}(V, D) & =-R+q \cdot S(\alpha V, \alpha D, T) \\
& \simeq-R+q\left(\frac{4 S_{2}(\alpha V, \alpha D, T)-s(\alpha V, \alpha D, T)}{3}\right)
\end{aligned}
$$

Symmetrically, if we consider that firm B (Leader) realizes the R\&D investment at time $t_{0}$ and player $\mathrm{A}$ postpones its decision, the firm $\mathrm{B}$ payoff will be:

$$
\begin{aligned}
L_{A}(V, D) & =-R+p \cdot S(\alpha V, \alpha D, T) \\
& \simeq-R+p\left(\frac{4 S_{2}(\alpha V, \alpha D, T)-s(\alpha V, \alpha D, T)}{3}\right)
\end{aligned}
$$

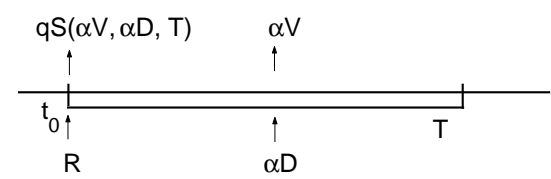

Figure 3: Leader's payoff

\subsection{The A and B payoffs when both firms wait to invest.}

Finally, we suppose that both players decide to delay their R\&D investment decision at time $t_{1}$ and, specifically, we can assume that there is not information revelation and consequently $\rho(Y, X)=\rho(X, Y)=0$. As we have seen in simultaneous case, we can setting that $\mathrm{A}$ and $\mathrm{B}$ share the market equally and so $\alpha=\frac{1}{2}$. Then, after the investment $R$ in $t_{1}$, each player holds in case of R\&D success the development option $S\left(\frac{1}{2} V, \frac{1}{2} D, \tau\right)$ to invest $\frac{1}{2} D$ at anytime before $T$ and claims a market share $\frac{1}{2} V$. So, at time $t_{0}$, the $\mathrm{A}$ and $\mathrm{B}$ payoffs are CAEO with maturity $t_{1}$, exercise price equal to $R=\varphi D$ and the underlying asset is the development option $S\left(\frac{1}{2} V, \frac{1}{2} D, T\right)$ with probability $q$ and $p$ respectively, as illustrated in the Figs $4(\mathrm{a})$ and $4(\mathrm{~b})$.

Thus, $\mathrm{A}$ and $\mathrm{B}$ payoffs at time $t_{0}$ are given by:

$$
\begin{aligned}
& W_{A}(V, D)=C\left(q \cdot S\left(\frac{1}{2} V, \frac{1}{2} D, \tau\right), \varphi D, t_{1}\right) \\
& W_{B}(V, D)=C\left(p \cdot S\left(\frac{1}{2} V, \frac{1}{2} D, \tau\right), \varphi D, t_{1}\right)
\end{aligned}
$$

Using the Eq.(8) we can determine the firms A and B waiting payoffs as:

$$
W_{A}(V, D) \simeq \frac{4 c_{2}\left(q S_{2}\left(\frac{1}{2} V, \frac{1}{2} D, \tau\right), \varphi D, t_{1}\right)-c\left(q S\left(\frac{1}{2} V, \frac{1}{2} D, \tau\right), \varphi D, t_{1}\right)}{3}
$$




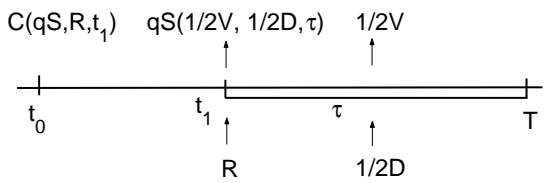

(a) Firm A's payoff

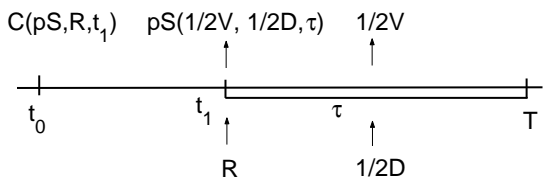

(b) Firm B's payoff

Figure 4: A and B payoffs in case waiting to invest

$$
W_{B}(V, D) \simeq \frac{4 c_{2}\left(p S_{2}\left(\frac{1}{2} V, \frac{1}{2} D, \tau\right), \varphi D, t_{1}\right)-c\left(p S\left(\frac{1}{2} V, \frac{1}{2} D, \tau\right), \varphi D, t_{1}\right)}{3}
$$

So, the appendix (A) shows the Matlab algorithm to determine the firms A and B waiting payoffs through Montecarlo simulation. It's sufficient to consider that information revelation $\rho(X, Y)=0$ and $\alpha=\frac{1}{2}$.

\subsection{Final payoffs at time $t_{0}$}

The two-by-two matrix represented in the Fig.5 summarizes the final payoffs. The first value in each cell indicates the strategic investment opportunity for $\mathrm{A}$ at time $t_{0}$, while the second represents the firm B's value. We can distinguish four basic cases: (i) when both firms decide to postpone the R\&D investment at time $t_{1}$; (ii) and (iii) when one firm invests first (as a Leader) and the other decides to invest later (as a Follower); ( iv) when both firms decide to invest simultaneously in R\&D at time $t_{0}$.

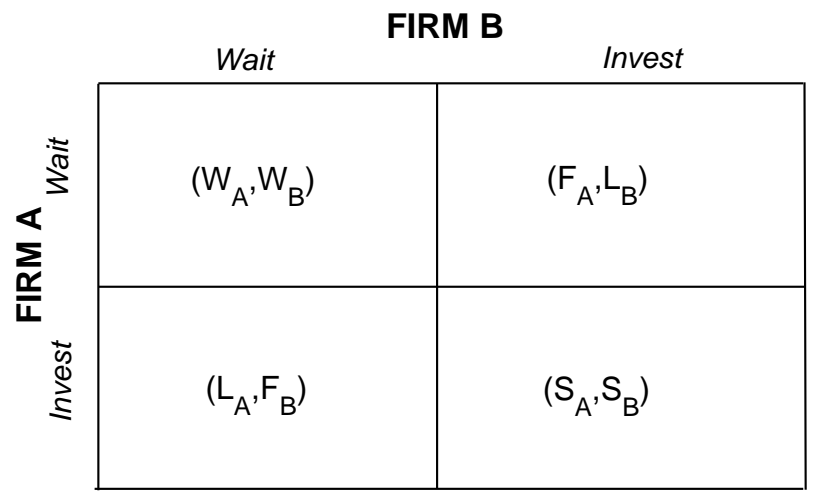

Figure 5: Final payoffs at time $t_{0}$

\section{Real Applications}

\subsection{Assumptions and Inputs}

This model can be applied to analyse industries such as high-tech, pharmaceutical, telecommunication, oil, in which competitors can substantially influence a firms investment opportunity. In fact, a firm may pre-empt competition and capture a significant share of the market $\alpha>\frac{1}{2}$ by setting the R\&D investment early on. This is 
an important source of advantage that may establish a sustainable strategic position. But, the firm that delays investment, can derive information about its $R \& D$ success from observing the R\&D performance of the other player.

So, to illustrate the concepts and equations presented, we develop a numerical example for the competitive R\&D game between firms A and B with the following parameters:

- R\&D Investment: $R=150000 \$$;

- Development Investment: $D=400000 \$$;

- Market and Costs Volatility: $\sigma_{v}=0.90 ; \quad \sigma_{d}=0.23$;

- Proportion of $D$ required for $R: \varphi=\frac{R}{D}=0.375$

- Correlation between $V$ and $D: \rho_{v d}=0.15$;

- Dividend-Yields of $V$ and $D: \quad \delta_{v}=0.15 ; \quad \delta_{d}=0$;

- Expiration Time of Compound Option: $t_{1}=0.5$ years;

- Expiration Time of Simple Option: $T=3$ years;

- A and B success probability: $q=0.60 ; \quad p=0.55$;

- Information Revelation: $\rho(X, Y)=\rho(Y, X)=0.70$;

- Leader's Market Share: $\alpha=0.60$;

- Critical Price $K=1.6722$ :

We consider five expected total market values $V: 800000 \$$ (low expected return), $1000000 \$, 1200000 \$$ (medium expected return) and $1400000 \$$ and $1600000 \$$ (high expected return). $V$ corresponds to present value of the expected cash flows deriving by R\&D innovations. We assume that $V$ follows the Brownian motion presented in Eq.(1).

The total investment cost $D$ is the exercise price for the development option. We consider that the investment cost is proportional to market share, namely if the firm's market share is $\alpha$ then its investment cost will be $\alpha D$. We assume that $D$ follows the Brownian motion process defined in Eq.(2). The total current value of $D$ is $400000 \$$ and it can be spent at anytime before $T$.

The R\&D investment $R$ can be realized at time $t_{0}$ or $t_{1}$. If it is made in $t_{0}$, then $R=150000 \$$ otherwise the investment $R$ assumes the identical stochastic process of $D$, except that it occurs at time $t_{1}$ and it is proportional to $\varphi=0.375$ of $D$.

Appropriately, we assume that the volatility of quoted shares and traded options is an adequate proxy for the volatility of asset $V$ and investment cost $D$. As the R\&D investments present a high uncertainty about their results, we assume that $\sigma_{v}=0.90$ and the cost volatility is $\sigma_{d}=0.23$.

According to financial options, $\delta$ denotes the opportunity cost in holding the option instead of the stock. So, in real option world, $\delta_{v}$ is the opportunity cost of deferring the project and $\delta_{d}$ is the "dividend yield" on asset $D$. As at the beginning the cash flows are very low, so we assume that $\delta_{v}=0.15$ and $\delta_{d}=0$.

The time to maturity $T$ denotes project's deferment option after that each opportunity disappears and we adopt $T=3$ years. Moreover, we state that Follower needs about six months to know the Leader's outcome and consequently to receive the information revelation. So we assume that $t_{1}=0.5$ years.

$K$ denotes the critical price value that makes indifferent the exercise or not at middle time $\frac{\tau}{2}$ of a PSAEO $S_{2}\left(V, D, \frac{\tau}{2}\right)$. So to determine $K$ it is sufficient to use Eq. (5) with $T=\tau$. For our adapted numbers it results $K=1.6722$.

Finally, we consider that firm A has an higher and more efficient Know-How than firm $\mathrm{B}$ and so, the firm A's success probability is $q=0.60$ while the firm B's one is $p=0.55$. 


\subsection{Empirical Results}

The Table 1 shows the Montecarlo simulation assuming the several overall market values. In particular way we compute, for each player, four Montecarlo simulations and, to determine the final Follower and the Waiting strategic payoffs, we compute the average value. We assume that the number of simulations $n$ is equal to 100000 . As it is shown in Cortelezzi \& Villani (2009), this simulations number allows us to obtain a very low variance and to improve the efficiency of computations.

\begin{tabular}{lrrrrr}
\hline \multicolumn{1}{c}{ Strategy } & $1^{\text {st }} \mathrm{MC}$ & $2^{\text {nd }} \mathrm{MC}$ & \multicolumn{1}{c}{$3^{\text {rd }} \mathrm{MC}$} & $4^{\text {th }} \mathrm{MC}$ & Average Value \\
\hline$F_{A}(800000)$ & 26620 & 26525 & 26573 & 26663 & $\mathbf{2 6 5 9 5}$ \\
$F_{B}(800000)$ & 23936 & 23862 & 23916 & 23999 & $\mathbf{2 3 9 2 8}$ \\
$W_{A}(800000)$ & 30760 & 30675 & 30777 & 30875 & $\mathbf{3 0 ~ 7 7 2}$ \\
$W_{B}(800000)$ & 25191 & 25133 & 25227 & 25323 & $\mathbf{2 5 2 1 9}$ \\
& & & & & \\
$F_{A}(1000000)$ & 47146 & 47147 & 47103 & 47087 & $\mathbf{4 7 ~ 1 2 0}$ \\
$F_{B}(1000000)$ & 43232 & 43060 & 43024 & 42988 & $\mathbf{4 3 ~ 0 7 6}$ \\
$W_{A}(1000000)$ & 56355 & 56123 & 56089 & 56004 & $\mathbf{5 6 ~ 1 4 3}$ \\
$W_{B}(1000000)$ & 47146 & 46925 & 46900 & 46780 & $\mathbf{4 6 9 3 8}$ \\
& & & & & \\
$F_{A}(1200000)$ & 72288 & 72286 & 71908 & 72176 & $\mathbf{7 2 ~ 1 6 4}$ \\
$F_{B}(1200000)$ & 66707 & 66711 & 66359 & 66608 & $\mathbf{6 6 5 9 6}$ \\
$W_{A}(1200000)$ & 87566 & 87618 & 87150 & 87484 & $\mathbf{8 7 4 5 5}$ \\
$W_{B}(1200000)$ & 74349 & 74369 & 73977 & 74261 & $\mathbf{7 4 2 3 9}$ \\
& & & & & \\
$F_{A}(1400000)$ & 100510 & 100750 & 100510 & 100420 & $\mathbf{1 0 0 5 4 8}$ \\
$F_{B}(1400000)$ & 93460 & 93687 & 93460 & 93356 & $\mathbf{9 3 4 9 1}$ \\
$W_{A}(1400000)$ & 123240 & 123530 & 123240 & 123030 & $\mathbf{1 2 3} \mathbf{2 6 0}$ \\
$W_{B}(1400000)$ & 105810 & 106060 & 105810 & 105650 & $\mathbf{1 0 5} \mathbf{8 3 3}$ \\
& & & & & \\
$F_{A}(1600000)$ & 130940 & 131290 & 131430 & 131440 & $\mathbf{1 3 1 2 7 5}$ \\
$F_{B}(1600000)$ & 122380 & 122720 & 122830 & 122870 & $\mathbf{1 2 2} \mathbf{7 0 0}$ \\
$W_{A}(1600000)$ & 161490 & 162000 & 162020 & 162130 & $\mathbf{1 6 1 9 1 0}$ \\
$W_{B}(1600000)$ & 139850 & 140290 & 140330 & 140460 & $\mathbf{1 4 0 2 3 3}$ \\
\hline
\end{tabular}

Table 1: Simulated Values of Follower and Waiting Strategies

The Tables 2 and 3 summarize the strategic A and B payoffs considering the several expected total market values. The Figs. 6 and 7 show the A and B strategic values. We can observe that, when the expected market value $V=0$, the simple and the compound American exchange option values are zero and so it results that $L_{i}(0)=S_{i}(0)=-R$ and $F_{i}(0)=W_{i}(0)=0$, for $i=A, B$. Now, to determine the several Nash equilibriums, we introduce the critical market values that realize the equality among the four strategic values. We define by $V_{W A}^{*}$ and $V_{W B}^{*}$ the critical market values that make $L_{i}\left(V_{W i}^{*}\right)=W_{i}\left(V_{W i}^{*}\right)$, for $i=A, B$ and by $V_{S A}^{*}$ and $V_{S B}^{*}$ the critical market values such that $F_{i}\left(V_{S i}^{*}\right)=F_{i}\left(V_{S i}^{*}\right)$, for $i=A, B$. Through Figs. 6 and 


\begin{tabular}{lcccc}
\hline Market & Leader's Value & Follower's Value & Simultaneous Value & Waiting Value \\
Value $V$ & $L_{A}$ & $F_{A}$ & $S_{A}$ & $W_{A}$ \\
\hline 800000 & -4474 & 26595 & -28728 & 30772 \\
1000000 & 48152 & 47120 & 15126 & 56143 \\
1200000 & 102894 & 72164 & 60745 & 87455 \\
1400000 & 159113 & 100548 & 107594 & 123260 \\
1600000 & 216402 & 131275 & 155335 & 161910 \\
\hline
\end{tabular}

Table 2: Firm A's final payoffs assuming $\alpha=0.60$ and $\rho(X, Y)=0.70$

\begin{tabular}{ccccc}
\hline Market & Leader's Value & Follower's Value & Simultaneous Value & Waiting Value \\
Value $V$ & $L_{B}$ & $F_{B}$ & $S_{B}$ & $W_{B}$ \\
\hline 800000 & -16601 & 23928 & -38834 & 25219 \\
1000000 & 31639 & 43076 & 1366 & 46938 \\
1200000 & 81819 & 66596 & 43183 & 74239 \\
1400000 & 133354 & 93491 & 86128 & 105833 \\
1600000 & 185869 & 122700 & 129891 & 140233 \\
\hline
\end{tabular}

Table 3: Firm B's final payoffs assuming $\alpha=0.60$ and $\rho(X, Y)=0.70$

7, we obtain:

$V_{W A}^{*} \simeq 1070000 ; \quad V_{W B}^{*} \simeq 1130000 ; \quad V_{S A}^{*} \simeq 1320000 ; \quad V_{S B}^{*} \simeq 1490000$.

When the expected market value $V<V_{W A}^{*}$, we have the following inequality among the strategic values:

$$
L_{A}(V)<W_{A}(V) ; \quad L_{B}(V)<W_{B}(V) ; \quad F_{A}(V)>S_{A}(V) ; \quad F_{B}(V)>S_{B}(V) ;
$$

So, using this inequality, we have one Nash equilibrium $\left(W_{A}, W_{B}\right)$. For instance, assuming that the expected market value is equal to $V=800000$ (low return), the two by two matrix represented in Fig. $8\left(\right.$ a) shows the $\left(W_{A}, W_{B}\right)$ Nash equilibrium in which firms A and B prefer to wait for best market evolutions and so they decide to delay their R\&D investment decision at time $t_{1}$.

Instead, if the expected market value $V>V_{S B}^{*}$, it results the following inequality among the stratigic values:

$$
L_{A}(V)>W_{A}(V) ; \quad L_{B}(V)>W_{B}(V) ; \quad F_{A}(V)<S_{A}(V) ; \quad F_{B}(V)<S_{B}(V) ;
$$

So, assuming that the expected market value $V=1600000$ (high return), there is one Nash equilibrium $\left(S_{A}, S_{B}\right)$ as shown in the Fig. $8($ d). Both firms decide to invest simultaneously in $\mathrm{R} \& \mathrm{D}$ at time $t_{0}$ to take advantage of high market value.

If we consider that the overall expected market value $V \in] V_{W A}^{*}, V_{W B}^{*}[$, the relation among the strategic payoffs is:

$$
L_{A}(V)>W_{A}(V) ; \quad L_{B}(V)<W_{B}(V) ; \quad F_{A}(V)>S_{A}(V) ; \quad F_{B}(V)>S_{B}(V) ;
$$

In this case we have one Nash equilibriums $\left(L_{A}, F_{B}\right)$. Specifically, the firm with the highest success probability (firm A) realizes the $\mathrm{R} \& \mathrm{D}$ investment at time $t_{0}$ earlier 


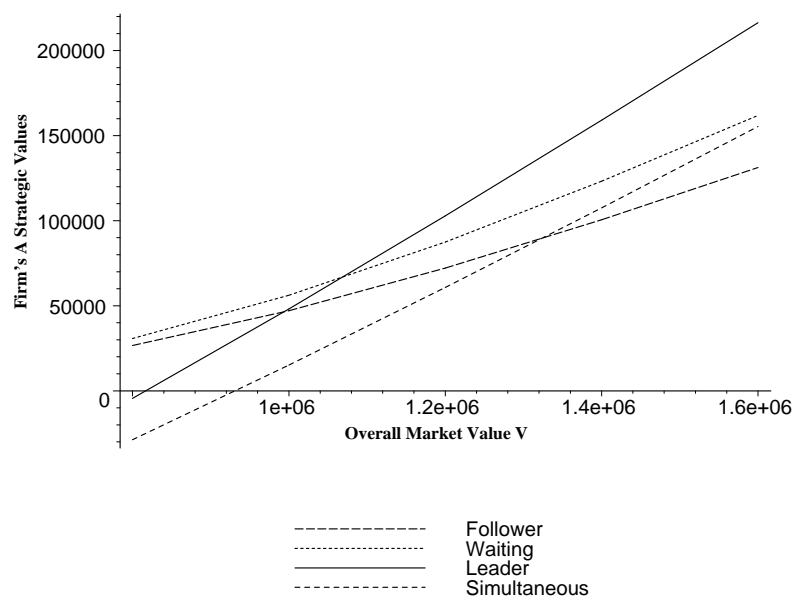

Figure 6: Firm's A Strategic Values

that other one (firm B) that postpones its R\&D investment decision at time $t_{1}$ waiting better information. Moreover, if we assume that $V \in] V_{S A}^{*}, V_{S B}^{*}$ [, we have the following relation among the strategic payoffs:

$$
L_{A}(V)>W_{A}(V) ; \quad L_{B}(V)>W_{B}(V) ; \quad F_{A}(V)<S_{A}(V) ; \quad F_{B}(V)>S_{B}(V) ;
$$

Also in this case, using the above relations, we have one Nash equilibrium $\left(L_{A}, F_{B}\right)$. For instance, if $V=1400000$, the Fig. 8(c) shows that there exists one Nash equilib$\operatorname{rium}\left(L_{A}, F_{B}\right)$.

Finally, if we assume that $V \in] V_{W B}^{*}, V_{S A}^{*}[$, we have the following inequality among the strategic values:

$$
L_{A}(V)>W_{A}(V) ; \quad L_{B}(V)>W_{B}(V) ; \quad F_{A}(V)>S_{A}(V) ; \quad F_{B}(V)>S_{B}(V) ;
$$

In this case we have two Nash equilibriums: $\left(L_{A}, F_{B}\right)$ and $\left(F_{A}, L_{B}\right)$. In the first equilibrium firm A invests immediately at time $t_{0}$ while $\mathrm{B}$ postpones its $\mathrm{R} \& \mathrm{D}$ decision at time $t_{1}$ waiting better information, vice versa in the second equilibrium. If we consider that $V=1200000$, we have two Nash equilibriums as it is represented in the Fig. 8(b).

\section{The effects of $\rho(X, Y), \alpha$ and $\delta_{v}$ on the equilibriums}

As we have seen above, in the range game $\left[V_{W A}^{*}, V_{S B}^{*}\right]$ we have one Nash equilibrium $\left(L_{A}, F_{B}\right)$ or two Nash equilibriums $\left(L_{A}, F_{B}\right) ;\left(F_{A}, L_{B}\right)$ that we can solve by mixed strategies. Now we are interested to analyse the effects that the information revelation $\rho(X, Y)$, the first mover's advantage $\alpha$ and the dividend yield $\delta_{v}$ have on Nash equilibriums of both players.

First of all, it is obvious that the strategic payoffs using American exchange options are bigger then European one since American options give the managerial flexibility value to realize the investment $D$ prior to maturity $T$. In particular way, comparing the results given in Villani (2008), we can remark that the critical market values using 


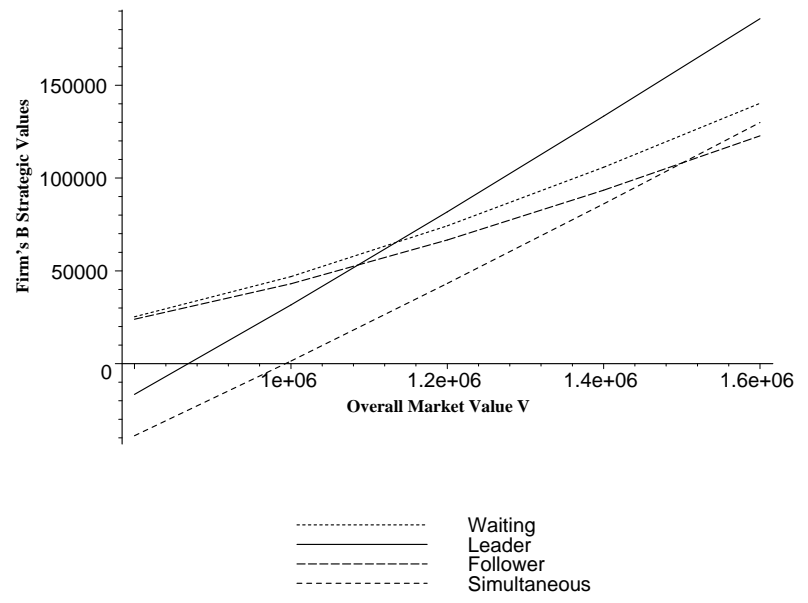

Figure 7: Firm's B Strategic Values

American exchange options $V_{W A}^{*}$ and $V_{S B}^{*}$ go down with respect to European options and the length of range game $\left[V_{W A}^{*}, V_{S B}^{*}\right] \simeq[1070000,1490000]=420000$ is smaller then $[1349400,1898700]=549300$ using European options. So we can state that, using the managerial flexibility, both firms reduce the critical market values that bound both the opportunity to delay the R\&D investment decision (wait and see policy) and the simultaneous investment implementation. So, with American options, the R\&D investment can be realized at time $t_{0}$ when $V=1070000 \$$ instead of $V=1349400 \$$. Moreover, when the dividend yields $\delta_{d}$ and $\delta_{v}$ go to zero, then the CAEO and SAEO prices are equal to CEEO (see Carr (1988)) and SEEO (see McDonald \& Siegel (1985)) respectively, since there is not the incentive to exercise the American option prior to maturity date $T$. So for our adapted number, assuming that $\delta_{v}=0$, we have that $V_{W A}^{*} \simeq 860000$ and $V_{S B}^{*} \simeq 1305000$.

The Table 4 shows the effects that the information revelation has got on the game ranges. To simplify, we assume that $\rho(X, Y)=\rho(Y, X)$. The conditions to respect to have $0 \leq p^{+} \leq 1$ and $0 \leq p^{-} \leq 1$ is that:

$$
0 \leq \rho(X, Y) \leq \min \left\{\sqrt{\frac{p(1-q)}{q(1-p)}}, \sqrt{\frac{q(1-p)}{p(1-q)}}\right\}
$$

In our applications it results that $0 \leq \rho(X, Y) \leq 0.9026$. We can observe that the Leader and Waiting payoffs are independent by $\rho(X, Y)$ and so the critical market values $V_{W A}^{*}$ and $V_{W B}^{*}$ do not change and therefore the length of range $\left[V_{W A}^{*}, V_{W B}^{*}\right]$ is always about $60000 \$$. But, if the information revelation increases, then the game ranges $] V_{W B}^{*}, V_{S A}^{*}$ [ (in which we have two Nash equilibriums) and $] V_{S A}^{*}, V_{S B}^{*}$ [ (in which we have one Nash equilibrium) enlarge.

The Table 5 shows the effects that the first mover's advantage has on the critical market values and in particular way we can note that, if the Leader's market share $\alpha$ increases, then all the critical market values go down. When $\alpha=1$ then the Follower's strategy values zero since its market share is $1-\alpha=0$. 


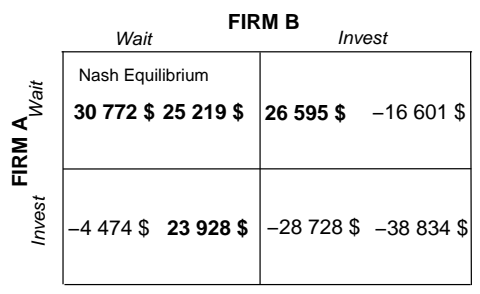

(a) I Case: $V=800000 \$$

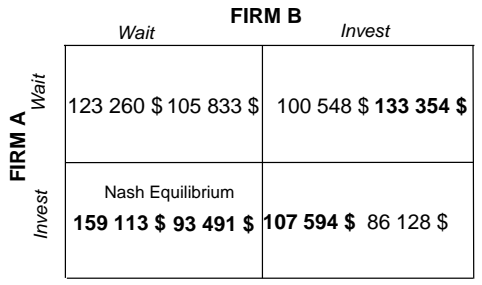

(c) III Case: $V=1400000 \$$

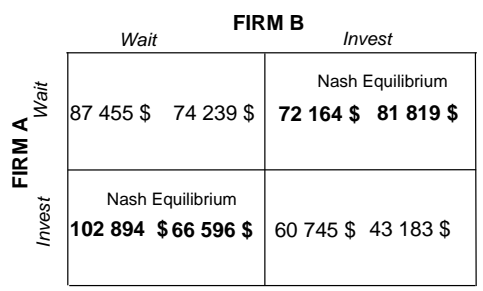

(b) II Case: $V=1200000 \$$

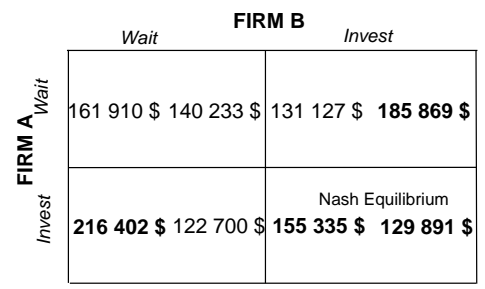

(d) IV Case: $V=1600000 \$$

Figure 8: Final payoffs

\begin{tabular}{cccccc}
\hline$\rho(X, Y)$ & $V_{S A}^{*}$ & $V_{S B}^{*}$ & $V_{W B}^{*}-V_{W A}^{*}$ & $V_{S A}^{*}-V_{W B}^{*}$ & $V_{S B}^{*}-V_{S A}^{*}$ \\
\hline 0 & 1155000 & 1228000 & 60000 & 25000 & 73000 \\
0.10 & 1165000 & 1262000 & 60000 & 35000 & 97000 \\
0.30 & 1203000 & 1307000 & 60000 & 73000 & 104000 \\
0.50 & 1235000 & 1380000 & 60000 & 105000 & 145000 \\
0.70 & 1320000 & 1490000 & 60000 & 190000 & 170000 \\
0.90 & 1439000 & 1690000 & 60000 & 309000 & 251000 \\
\hline
\end{tabular}

Table 4: Variation of Information Revelation with $\alpha=0,60$ and $\delta_{v}=0.15$

\begin{tabular}{lrrrr}
\hline$\alpha$ & \multicolumn{1}{c}{$V_{W A}^{*}$} & \multicolumn{1}{c}{$V_{W B}^{*}$} & \multicolumn{1}{c}{$V_{S A}^{*}$} & \multicolumn{1}{c}{$V_{S B}^{*}$} \\
\hline 0.60 & 1070000 & 1130000 & 1320000 & 1490000 \\
0.70 & 858000 & 906000 & 1070000 & 1161000 \\
0.80 & 742000 & 791000 & 975000 & 1042000 \\
0.90 & 662000 & 703000 & 935000 & 998000 \\
1 & 609000 & 645000 & 932000 & 993000 \\
\hline
\end{tabular}

Table 5: Variation of Leader's Market Share with $\rho(X, Y)=0.70$ and $\delta_{v}=0.15$ 


\section{Concluding Remarks.}

The R\&D investment is an important successful key for the firm performance. An R\&D investment opportunity is not held by one firm in isolation and so the competitive considerations become extremely important. The theory of option games combines two successful theories, namely real options and game theory. By real options we value an $\mathrm{R} \& \mathrm{D}$ investment opportunity using financial techniques and, in particular way, we use Montecarlo simulations to value an American exchange options that take into account the managerial flexibility to realize the investment $D$ at anytime before the maturity $T$. By the game theory, we consider strategic interactions between two firms. The first firm that invests, defined as the Leader, acquires a first mover advantage that we assume as a higher market share then Follower's one, that postpones the R\&D investment. But, in our model, we assume that Follower receives an information revelation from Leader's R\&D investment. Through the critical market values $V_{W A}^{*}, V_{W B}^{*}, V_{S A}^{*}$ and $V_{S B}^{*}$, we are able to determine the range game in which is optimal each strategy policy in Nash meaning and we have showed the effects that most important parameters have on the game. So, when $V<V_{W A}^{*}$ we have one Nash equilibrium $\left(W_{A}, W_{B}\right)$ and if $V>V_{S B}^{*}$ the optimal Nash policy is the simultaneous investment $\left(S_{A}, S_{B}\right)$ at time $t_{0}$. Moreover, if $V$ is in the ranges $] V_{W A}^{*}, V_{W B}^{*}$ [ and $] V_{S A}^{*}, V_{S B}^{*}$ [ we have one Nash equilibrium $\left(L_{A}, F_{B}\right)$ in which the firm with the highest success probability realizes the $\mathrm{R} \& \mathrm{D}$ investment earlier then other one, while in the interval $] V_{W B}^{*}, V_{S A}^{*}$ [ we have two Nash equilibriums: $\left(L_{A}, F_{B}\right)$ and $\left(F_{A}, L_{B}\right)$. In this case we need to use the mixed strategies to solve the game.

Acknowledgements Many thanks to CESifo sponsorship for the opportunity to present this paper at the Workshop on "Operating Uncertainty Using Real Options" held in Venice, 8-9 July 2009.

\section{A Montecarlo Simulation to determine Follower's payoff}

In this algorithm, we denote by ' $\mathrm{f}$ ' the proportion $\varphi$ of asset $D$ to determine the research investment $R$, by ' $\mathrm{pL}$ ' and ' $\mathrm{pF}$ ' the $\mathrm{R} \& \mathrm{D}$ success probability of Leader and Follower respectively, and by 'rev' the information revelation. Moreover, ' $n$ ' is the number of simulations and ' $\mathrm{K}$ ' denotes the critical market value that makes indifferent the exercise or not at middle time $\frac{\tau}{2}$ a PSAEO $S_{2}(V, D, \tau)$.

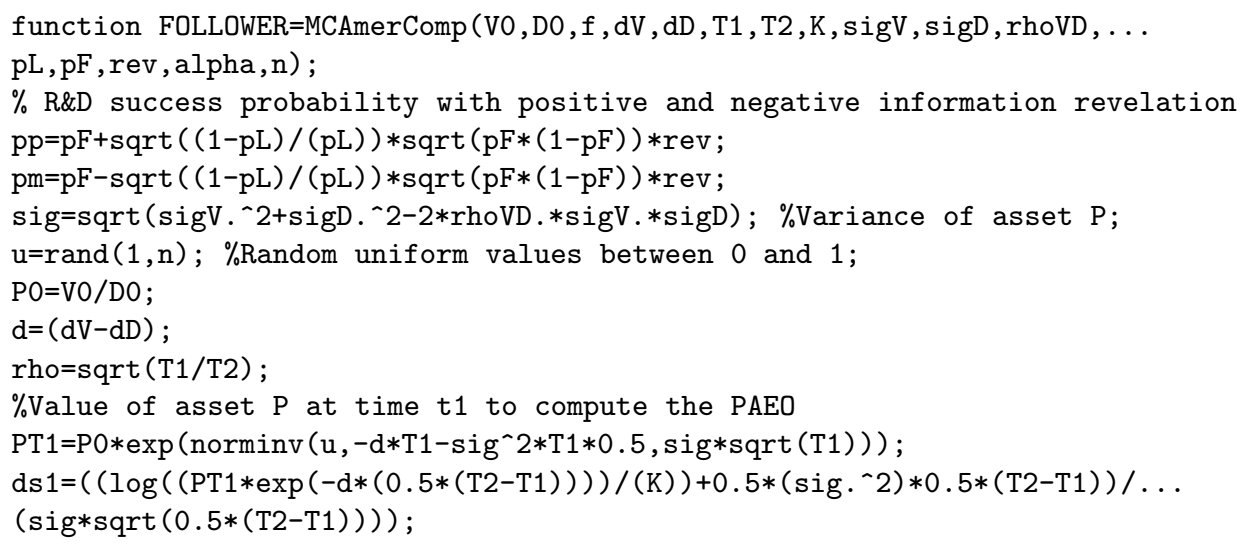




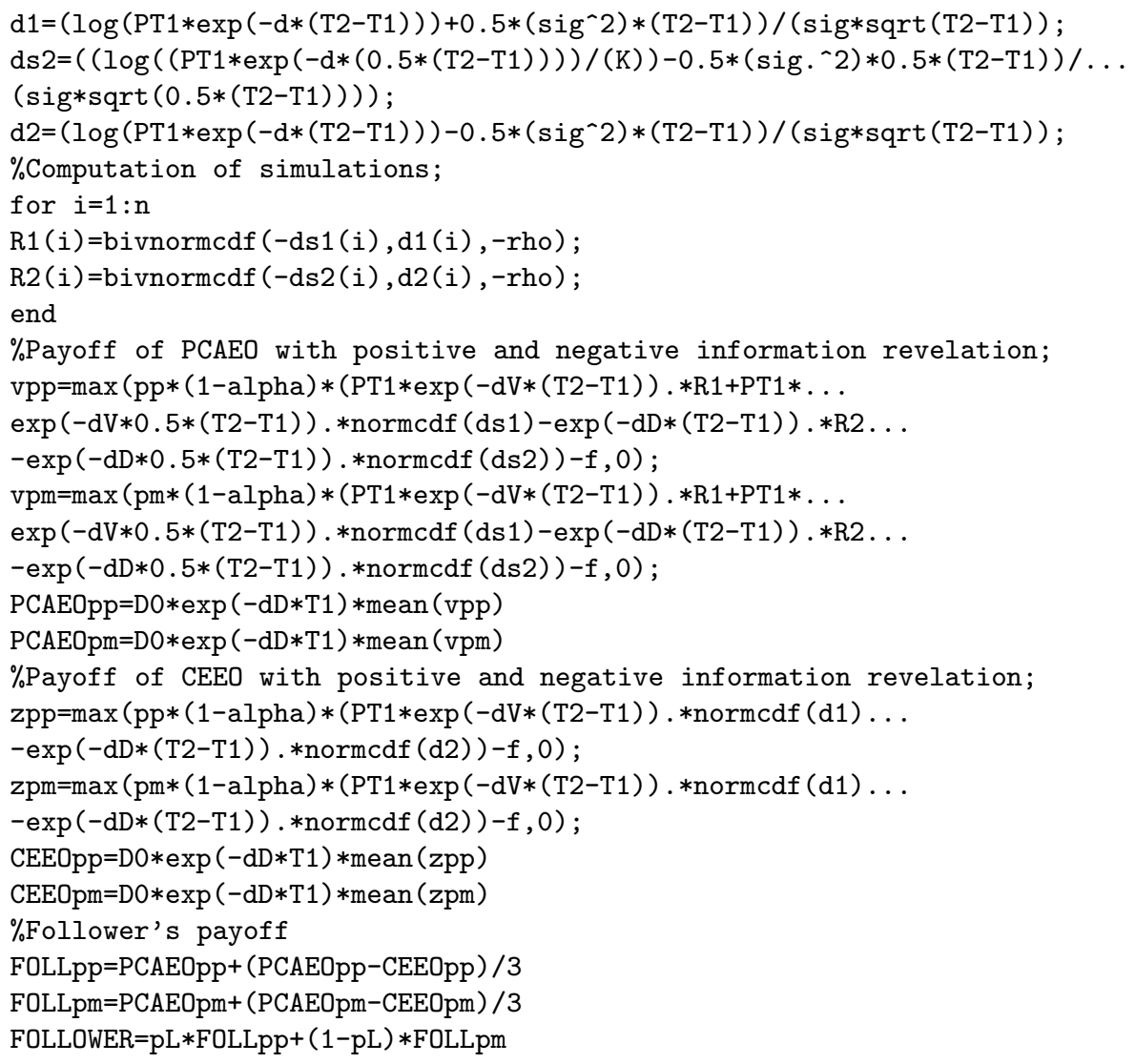

\section{References}

Armada, M.R., Kryzanowsky, L. \& Pereira, P.J., (2007). A Modified Finite-Lived American Exchange Option Methodology Applied to Real Options Valuation, Global Finance Journal, Vol. 17, Issue 3, 419-438.

Carr, P. (1988).The Valuation of Sequential Exchange Opportunities, The Journal of Finance, Vol. 43, Issue 5, 1235-1256.

Carr, P. (1995). The Valuation of American Exchange Options with Application to Real Options, in: Real Options in Capital Investment: Models, Strategies and Applications ed. by Lenos Trigeorgis, Westport Connecticut, London, Praeger.

Copeland, T. and V. Antikarov (2003). Real Options: a practitioner's guide, New York, Texere.

Cortelezzi, F. and G. Villani (2008). Strategic Technology Adoption and Market Dynamics as Option Games, The Icfai Journal of Industrail Economics, Vol. 5, Issue $4,7-27$. 
Cortelezzi, F. and G. Villani (2009). Valuation of REDD Sequential Exchange Options using Monte Carlo approach, Computational Economics, Vol. 33 Issue 3, 209-236.

Dias, M.A.G. (2004). Valuation of exploration and production assets: an overview of real options models, Journal of Petroleum Science and Engineering, Vol. 44, 93114.

Dias, M.A.G. and J.P. Teixeira (2004). Continuous-time option games part 2: oligopoly, war of attrition and bargaining under uncertainty. Working Paper, PUCRio, presented at 8th Annual International Conference on Real Options, Montreal, June 2004.

Geske, R. (1979). The Valuation of Compound Options, Journal of Financial Economics, Vol. 7, 63-81.

Lee, M.H. (1997). Valuing Finite-Maturity Investment-Timing Options, Financial Management, Vol. 26, Issue 2, 58-66.

Majd, S. and R.S. Pindyck (1987). Time to Build, Option Value and Investment Decisions, Journal of Financial Economics, Vol. 18, Issue 1, 7-27.

Margrabe, W. (1978). The Value of an Exchange Option to Exchange One Asset for Another, The Journal of Finance, Vol. 33, Issue 1, 177-186.

McDonald, R.L. and D.R. Siegel (1985). Investment and the Valuation of Firms When There is an Option to Shut Down, International Economic Review, Vol. 28, Issue 2, 331-349.

Trigeorgis, L. (1991), Anticipated competitive entry and early preemptive investment in deferrable projects, Journal of Economics and Business, Vol. 43, Issue 2, 143-156.

Villani, G. (2008). An RED Investment Game under uncertainty in Real Option Analysis, Computational Economics, Vol. 32, Issue 2-3, 199-219. 


\section{CESifo Working Paper Series}

for full list see www.cesifo-group.org/wp

(address: Poschingerstr. 5, 81679 Munich, Germany, office@cesifo.de)

2665 Claudia M. Buch and Christian Pierdzioch, Low Skill but High Volatility?, May 2009

2666 Hendrik Jürges, Kerstin Schneider, Martin Senkbeil and Claus H. Carstensen, Assessment Drives Learning: The Effect of Central Exit Exams on Curricular Knowledge and Mathematical Literacy, June 2009

2667 Eric A. Hanushek and Ludger Woessmann, Schooling, Cognitive Skills, and the Latin American Growth Puzzle, June 2009

2668 Ourania Karakosta, Christos Kotsogiannis and Miguel-Angel Lopez-Garcia, Does Indirect Tax Harmonization Deliver Pareto Improvements in the Presence of Global Public Goods?, June 2009

2669 Aleksandra Riedl and Silvia Rocha-Akis, Testing the Tax Competition Theory: How Elastic are National Tax Bases in OECD Countries?, June 2009

2670 Dominique Demougin and Carsten Helm, Incentive Contracts and Efficient Unemployment Benefits, June 2009

2671 Guglielmo Maria Caporale and Luis A. Gil-Alana, Long Memory in US Real Output per Capita, June 2009

$2672 \mathrm{Jim}$ Malley and Ulrich Woitek, Productivity Shocks and Aggregate Cycles in an Estimated Endogenous Growth Model, June 2009

2673 Vivek Ghosal, Business Strategy and Firm Reorganization under Changing Market Conditions, June 2009

2674 Francesco Menoncin and Paolo M. Panteghini, Retrospective Capital Gains Taxation in the Real World, June 2009

2675 Thomas Hemmelgarn and Gaëtan Nicodème, Tax Co-ordination in Europe: Assessing the First Years of the EU-Savings Taxation Directive, June 2009

2676 Oliver Himmler, The Effects of School Competition on Academic Achievement and Grading Standards, June 2009

2677 Rolf Golombek and Michael Hoel, International Cooperation on Climate-Friendly Technologies, June 2009

2678 Martin Cave and Matthew Corkery, Regulation and Barriers to Trade in Telecommunications Services in the European Union, June 2009

2679 Costas Arkolakis, A Unified Theory of Firm Selection and Growth, June 2009 
2680 Michelle R. Garfinkel, Stergios Skaperdas and Constantinos Syropoulos, International Trade and Transnational Insecurity: How Comparative Advantage and Power are Jointly Determined, June 2009

2681 Marcelo Resende, Capital Structure and Regulation in U.S. Local Telephony: An Exploratory Econometric Study; June 2009

2682 Marc Gronwald and Janina Ketterer, Evaluating Emission Trading as a Policy Tool Evidence from Conditional Jump Models, June 2009

2683 Stephan O. Hornig, Horst Rottmann and Rüdiger Wapler, Information Asymmetry, Education Signals and the Case of Ethnic and Native Germans, June 2009

2684 Benoit Dostie and Rajshri Jayaraman, The Effect of Adversity on Process Innovations and Managerial Incentives, June 2009

2685 Peter Egger, Christian Keuschnigg and Hannes Winner, Incorporation and Taxation: Theory and Firm-level Evidence, June 2009

2686 Chrysovalantou Milliou and Emmanuel Petrakis, Timing of Technology Adoption and Product Market Competition, June 2009

2687 Hans Degryse, Frank de Jong and Jérémie Lefebvre, An Empirical Analysis of Legal Insider Trading in the Netherlands, June 2009

2688 Subhasish M. Chowdhury, Dan Kovenock and Roman M. Sheremeta, An Experimental Investigation of Colonel Blotto Games, June 2009

2689 Alexander Chudik, M. Hashem Pesaran and Elisa Tosetti, Weak and Strong Cross Section Dependence and Estimation of Large Panels, June 2009

2690 Mohamed El Hedi Arouri and Christophe Rault, On the Influence of Oil Prices on Stock Markets: Evidence from Panel Analysis in GCC Countries, June 2009

2691 Lars P. Feld and Christoph A. Schaltegger, Political Stability and Fiscal Policy - Time Series Evidence for the Swiss Federal Level since 1849, June 2009

2692 Michael Funke and Marc Gronwald, A Convex Hull Approach to Counterfactual Analysis of Trade Openness and Growth, June 2009

2693 Patricia Funk and Christina Gathmann, Does Direct Democracy Reduce the Size of Government? New Evidence from Historical Data, 1890-2000, June 2009

2694 Kirsten Wandschneider and Nikolaus Wolf, Shooting on a Moving Target: Explaining European Bank Rates during the Interwar Period, June 2009

2695 J. Atsu Amegashie, Third-Party Intervention in Conflicts and the Indirect Samaritan's Dilemma, June 2009

2696 Enrico Spolaore and Romain Wacziarg, War and Relatedness, June 2009 
2697 Steven Brakman, Charles van Marrewijk and Arjen van Witteloostuijn, Market Liberalization in the European Natural Gas Market - the Importance of Capacity Constraints and Efficiency Differences, July 2009

2698 Huifang Tian, John Whalley and Yuezhou Cai, Trade Sanctions, Financial Transfers and BRIC's Participation in Global Climate Change Negotiations, July 2009

2699 Axel Dreher and Justina A. V. Fischer, Government Decentralization as a Disincentive for Transnational Terror? An Empirical Analysis, July 2009

2700 Balázs Égert, Tomasz Koźluk and Douglas Sutherland, Infrastructure and Growth: Empirical Evidence, July 2009

2701 Felix Bierbrauer, Optimal Income Taxation and Public Goods Provision in a Large Economy with Aggregate Uncertainty, July 2009

2702 Marc Gronwald, Investigating the U.S. Oil-Macroeconomy Nexus using Rolling Impulse Responses, July 2009

2703 Ali Bayar and Bram Smeets, Government Deficits in the European Union: An Analysis of Entry and Exit Dynamics, July 2009

2704 Stergios Skaperdas, The Costs of Organized Violence: A Review of the Evidence, July 2009

2705 António Afonso and Christophe Rault, Spend-and-tax: A Panel Data Investigation for the EU, July 2009

2706 Bruno S. Frey, Punishment - and beyond, July 2009

2707 Michael Melvin and Mark P. Taylor, The Crisis in the Foreign Exchange Market, July 2009

2708 Firouz Gahvari, Friedman Rule in a Model with Endogenous Growth and Cash-inadvance Constraint, July 2009

2709 Jon H. Fiva and Gisle James Natvik, Do Re-election Probabilities Influence Public Investment?, July 2009

2710 Jarko Fidrmuc and Iikka Korhonen, The Impact of the Global Financial Crisis on Business Cycles in Asian Emerging Economies, July 2009

2711 J. Atsu Amegashie, Incomplete Property Rights and Overinvestment, July 2009

2712 Frank R. Lichtenberg, Response to Baker and Fugh-Berman's Critique of my Paper, "Why has Longevity Increased more in some States than in others?", July 2009

2713 Hans Jarle Kind, Tore Nilssen and Lars Sørgard, Business Models for Media Firms: Does Competition Matter for how they Raise Revenue?, July 2009 
2714 Beatrix Brügger, Rafael Lalive and Josef Zweimüller, Does Culture Affect Unemployment? Evidence from the Röstigraben, July 2009

2715 Oliver Falck, Michael Fritsch and Stephan Heblich, Bohemians, Human Capital, and Regional Economic Growth, July 2009

2716 Wladimir Raymond, Pierre Mohnen, Franz Palm and Sybrand Schim van der Loeff, Innovative Sales, R\&D and Total Innovation Expenditures: Panel Evidence on their Dynamics, July 2009

2717 Ben J. Heijdra and Jochen O. Mierau, Annuity Market Imperfection, Retirement and Economic Growth, July 2009

2718 Kai Carstensen, Oliver Hülsewig and Timo Wollmershäuser, Price Dispersion in the Euro Area: The Case of a Symmetric Oil Price Shock, July 2009

2719 Katri Kosonen and Gaëtan Nicodème, The Role of Fiscal Instruments in Environmental Policy, July 2009

2720 Guglielmo Maria Caporale, Luca Onorante and Paolo Paesani, Inflation and Inflation Uncertainty in the Euro Area, July 2009

2721 Thushyanthan Baskaran and Lars P. Feld, Fiscal Decentralization and Economic Growth in OECD Countries: Is there a Relationship?, July 2009

2722 Nadia Fiorino and Roberto Ricciuti, Interest Groups and Government Spending in Italy, 1876-1913, July 2009

2723 Andreas Wagener, Tax Competition, Relative Performance and Policy Imitation, July 2009

2724 Hans Fehr and Fabian Kindermann, Pension Funding and Individual Accounts in Economies with Life-cyclers and Myopes, July 2009

2725 Ernesto Reuben and Arno Riedl, Enforcement of Contribution Norms in Public Good Games with Heterogeneous Populations, July 2009

2726 Kurt Schmidheiny and Marius Brülhart, On the Equivalence of Location Choice Models: Conditional Logit, Nested Logit and Poisson, July 2009

2727 Bruno S. Frey, A Multiplicity of Approaches to Institutional Analysis. Applications to the Government and the Arts, July 2009

2728 Giovanni Villani, A Strategic R\&D Investment with Flexible Development Time in Real Option Game Analysis, July 2009 